\title{
Sentence-final word completion norms for European Portuguese children and adolescents
}

\author{
Ana P. Pinheiro, Ana P. Soares, and Montserrat Comesaña \\ University of Minho, Braga, Portugal \\ Margaret NiznikIEWICZ \\ Boston VA Healthcare System, Brockton, Massachusetts \\ and Harvard Medical School, Boston, Massachusetts \\ AND \\ ÓsCar F. Gonçalves \\ University of Minho, Braga, Portugal
}

\begin{abstract}
This study presents a set of sentence contexts and their cloze probabilities for European Portuguese children and adolescents. Seventy-three sentence contexts (35 low- and 38 high-constraint sentence stems) were presented to 90 children and 102 adolescents. Participants were asked to complete the sentence contexts with the first word that came to mind. For each sentence context, responses were listed and cloze probabilities of the words that were chosen to complete the sentence context were computed. Additionally, idiosyncratic and invalid responses (structural and semantic errors) were analyzed. A high degree of consistency in responses among the two age samples (children and adolescents) was found, along with a decrease of idiosyncratic and invalid responses in older participants. These results shed light on age-related changes in the effects of linguistic context on word production, and also in knowledge's representation. The full set of norms may be downloaded from http://brm.psychonomic-journals.org/content/supplemental.
\end{abstract}

How do we know that a cat can eat a mouse, but not a shark? The answer would depend on whether the shark in question is an ocean-dwelling predator or a biscuit for cats in the shape of a shark. And for the sentence context "They immediately swam to shore because they thought it was a ....", the word "shark" would be expected if the participant were provided, in the first place, with the context "Two teenage boys were swimming off the coast of Florida when they noticed a suspicious-looking dorsal fin." Semantic context thus has a crucial role in language comprehension. The way language helps to organize the knowledge of the world-representing objects, events, and relationships; arranging items in categories; and providing meaning tools - seems to be a unique human legacy and an evolutionary advantage (Lieberman, 2002).

Specifically, the ability to use sentence context in order to constrain semantic choices (words) is a crucial process in sentence comprehension, allowing the listener/reader to determine meanings and solve potential ambiguities. For example, classic models of semantic processing (e.g., Collins \& Loftus, 1975; Collins \& Quillian, 1969; Loftus, 1973 ) suggest that words are organized in a semantic network of interconnected nodes of related meanings. During sentence processing, components of the lexical network are activated by the phonological or orthographic input that the person is processing, as well as by the context that these words create. As the sentence progresses and the context emerges, inhibitory mechanisms suppress those nodes that were previously activated but no longer appropriately complete the sentence (Kimble et al., 2002; Stanovich \& West, 1981). More recent models, such as the parallel distributed processing (PDP) approach (Rogers \& McClelland, 2004), go further, by saying that a system of massively interconnected processing units underlies semantic processing. The pattern of activation between these units is then ruled by weighted connections among units. In addition, changes in these weights, as a consequence of daily experience or learning, are the basis for the development of semantic knowledge.

The basic assumptions of activation models of semantic memory are supported by several studies suggesting that human beings, besides being meaning creators, also generate expectations based on the linguistic input they are receiving (DeLong, Urbach, \& Kutas, 2005; Federmeier \& Kutas, 1999a, 1999b; Hagoort, Hald, Bastiaansen, \& Petersson, 2004; Kamide, Altmann, \& Haywood, 2003; Neely, 1991; Otten, Nieuwland, \& Van Berkum, 2007; Otten \& Van Berkum, 2007; Pickering \& Garrod, 2007; Taraban \& Mc-

A. P. Pinheiro, ana.pinheiro@psi.uminho.pt 
Clelland, 1988; Van Berkum, Brown, Zwitserlood, Kooijman, \& Hagoort, 2005; Van Berkum, Hagoort, \& Brown, 1999; Van Berkum, Zwitserlood, Hagoort, \& Brown, 2003; Wicha, Bates, Moreno, \& Kutas, 2003).

One task that has been widely used for testing the effects of semantic expectation (Williams \& Colombo, $1995)$, as well as the effects of semantic context (Bloom \& Fischler, 1980; McDonald \& Tamariz, 2002), is the sentence completion task. The pioneering work of Bloom and Fischler contributed to a better understanding of how word associations can be constrained by linguistic context. Traditionally, this task consists of asking participants to read a set of sentence contexts and to complete the last fragment with the first word that comes to mind (Taylor, 1953). The responses obtained through this task allow the computation of cloze probabilities - that is, the probability that a person will choose a word as an appropriate completion of a given sentence context (Taylor, 1953, 1956). This process reflects the effects emerging from multiple-level constraints (syntactic, semantic, and pragmatic) that will govern the choice of a word for a specific context (Connolly, Phillips, \& Forbes, 1995; Kohn \& Cragnolino, 1998; Lahar, Tun, \& Wingfield, 2004; van den Brink, Brown, \& Hagoort, 2001). If the sentence context is highly constraining (i.e., allowing one or very few plausible completion words), the cloze probability of that word will be higher than if the context provides low constraint (allowing several possible completions) (Schwanenflugel \& LaCount, 1988; Schwanenflugel \& Shoben, 1985).

Norms for sentence completion are currently available for English (e.g., Bloom \& Fischler, 1980; Schwanenflugel, 1986; Towse, Hamilton, Hitch, \& Hutton, 2000), French (Robichon, Besson, \& Faita, 1996), and Spanish (McDonald \& Tamariz, 2002), although no similar norms exist for European Portuguese.

These norms constitute a valuable resource for several areas of research, including psycholinguistics, human memory, and neuroscience (e.g., Federmeier, McLennan, de Ochoa, \& Kutas, 2002; Griffin \& Bock, 1998; Kleiman, 1980; Lahar et al., 2004; Stanovich \& West, 1983), allowing us to understand the cognitive and neurocognitive mechanisms underlying processes of language comprehension and production (e.g., Cramer, 1968). They have also been used for the study of clinical populationsnamely, those with aphasia (Berndt, Mitchum, Haendiges, \& Sandson, 1997), Alzheimer's disease (Nebes \& Brady, 1991), schizophrenia (Kircher et al., 2001), and posttraumatic stress disorder (Kimble et al., 2002). These norms are also useful for event-related potential studies of language that aim to understand the neural processes underlying language comprehension. Results of these studies show that expected sentence endings elicit smaller N400 amplitudes (an index of semantic integration and expectedness) than do unexpected endings (see, e.g., Curran, Tucker, Kutas, \& Posner, 1993; Federmeier \& Kutas, 1999a, 1999b; Kutas \& Hillyard, 1980).

The importance of these norms for studies on semantic memory structure is also well documented (e.g., Fed- ermeier, Kirson, Moreno, \& Kutas, 2001; Federmeier \& Kutas, 1999a, 1999b, 2001; Federmeier et al., 2002; Kounios \& Holcomb, 1992). Developmentally, differences in the words chosen to complete a given context (as in a sentence completion task) may be explained by changes in the structure and process of semantic memory. For example, studies have shown that the number of words produced in verbal fluency tasks increases with age (e.g., Bjorklund, 1987; Bjorklund \& Marchena, 1984), indicating an increase in vocabulary size (Kausler \& Puckett, 1980). Other studies showed lexical and conceptual changes at around 7-8 years of age (Carneiro, Albuquerque, Fernandez, \& Esteves, 2004; Cronin, 2002; Francis, 1972; Nelson, 1977; Petrey, 1977) —in particular, a higher number of syntagmatic responses (words that are associated in a syntactic sequence-e.g., cold-outside) than of paradigmatic responses (associates from the same grammatical class-e.g., cold-hot) in younger than in older children. A rise in the commonality of responses and paradigmatic responding, in both older children and adults, has also been reported (Rosenzweig, 1984; Sharp \& Cole, 1972)

Moreover, the organization of knowledge seems to change from thematic (items that share an interactive or functional relationship-e.g., dog-bone) to taxonomic (items that belong to the same category-e.g., river-lake) relationships (A. B. Markman \& Dietrich, 2000; E. M. Markman, 1990; E. M. Markman \& Hutchinson, 1984; Nelson, 1977; Smiley \& Brown, 1979), and lexical representations tend to become more segmental and less holistic, as vocabulary increases (Elbro, 1996; Storkel, 2002, 2009). There is also evidence pointing to changes in the relative influence of contextual and stimulus factors on word recognition as reading fluency develops, with young children relying more on contextual information to aid word recognition and adults showing increased automatic word processing abilities (Schwantes, Boesl, \& Ritz, 1980; West \& Stanovich, 1978; West, Stanovich, Feeman, \& Cunningham, 1983).

Together, these findings suggest that, throughout development, the structure of semantic memory undergoes changes not only in terms of the number of items in semantic networks, but also in terms of the richness of representations and items' accessibility (e.g., Bjorklund, 1985, 1987; Chi \& Ceci, 1987; Gathercole, Willis, Emslie, \& Baddeley, 1992; Munson, Swenson, \& Manthei, 2005; Schneider \& Pressley, 1997; Storkel, 2002, 2009; Swingley, 2003; Vicente, Castro, \& Walley, 2003). Also, they indicate that these changes are supported by the dynamic interaction of individual factors (e.g., maturation) and environmental variables (e.g., education) (see Thomas \& Karmiloff-Smith, 2002, 2003).

Because of the utility of sentence completion norms for several research domains, studies have already been conducted in different languages with the aim of developing these norms with an adult population (e.g., Bloom \& Fischler, 1980), but few have been conducted with children (Towse, Hutton, \& Hitch, 1997, 1998), and none in Portugal. 
The utility of age-adjusted norms is critical for the development of reliable research in psycholinguistics, as well as in developmental and neurolinguistics research (see also Lahar et al., 2004).

This study describes a set of 73 sentence contexts (with constraint varying from high to low) and their cloze probabilities for European Portuguese children and adolescents. One of its aims was also to compare the responses of children and adolescents in the sentence completion task, analyzing potential developmental changes in the number of valid and invalid responses, as well as in the number of singular words produced by each group for each sentence context. Three measures were used: (1) cloze probability (the number of times the same word was chosen by a specific group for a given sentence context, considering the size of that group); (2) idiosyncratic responses (the number of valid responses produced by only 1 individual of a given group for a specific sentence context); and (3) invalid responses (the number of inappropriate responses, at the structural or semantic level, produced by a given group for a specific sentence context). Age-related differences were expected. These differences would be consistent with previous studies suggesting developmental changes in the way semantic concepts are organized and used (e.g., Bjorklund \& Schneider, 1996; Macizo, Gómez-Ariza, \& Bajo, 2000), and age-related changes in (schematic and taxonomic) knowledge structures (e.g., Carneiro et al., 2004; Cronin, 2002; Francis, 1972; A. B. Markman \& Dietrich, 2000; E. M. Markman, 1990; E. M. Markman \& Hutchinson, 1984; Nelson, 1977; Petrey, 1977; Smiley \& Brown, 1979).

On the basis of the existing evidence, we expected an increase in cloze probability scores of final words with age, and a decrease in the number of idiosyncratic responses in the adolescents group. An increased consistency in word selection would suggest a higher robustness of knowledge structures as a consequence of age, education, and world experience. We also hypothesized that the number of semantic and structural errors would be higher in children than in adolescents. This would be consistent with previous studies suggesting that there is a refinement of knowledge structures throughout development (e.g., Bjorklund, 1987; Bjorklund \& Marchena, 1984; Chi \& Ceci, 1987; Gathercole et al., 1992; Munson et al., 2005; Schneider \& Pressley, 1997; Storkel, 2002, 2009; Swingley, 2003; Vicente et al., 2003), thought to affect memory processes and word selection, as in a sentence completion task.

\section{METHOD}

\section{Participants}

Ninety children (mean age $=9.19$ years, $S D=1.35$; age range, $6-11$ ) and 102 adolescents (mean age $=14.69$ years, $S D=1.94$; age range, 12-18) participated in this study. All participants were European Portuguese native speakers of both genders (children, 50 females and 40 males; adolescents, 73 females and 29 males). They were recruited in elementary and high schools in northern Portugal. All participants were monolingual or had knowledge in other languages equivalent to their educational level. None of them were identified by their teachers as having learning or intellectual disabilities.

\section{Materials}

Seventy-three sentence contexts were developed. All sentences had the same syntactic structure (subject and direct verb in the present tense-SVO). The number of words per sentence context was kept constant (four).

Sentence contexts were coded by two independent adult judges, graduates in Portuguese literature, as low-contextual-constraint sentences (e.g., "The woman smells a . .."), if they allowed for several appropriate endings, or as high-contextual-constraint sentences (e.g., "The girl is curling the ..."), if the semantic context was sufficiently restrictive to allow only one or two plausible endings. Differences in judges' assessments were resolved by consensus. However, in the situations in which there was no agreement between them, a third independent judge (also a graduate in Portuguese literature) decided the final rating. For all the sentences, interrater agreement was higher than $90 \%$. Thirty-five sentences were classified as lowconstraint, and 38 sentences were judged as high-constraint (see the supplemental materials).

A booklet with 73 sentence contexts was used to collect responses from participants. Sentence contexts from which the last word was missing were printed on white paper (Arial Narrow font, point size 13), with a blank space at the end of each context where participants could write down their responses. The order of the sentence contexts was pseudorandomized before presentation to the groups (in order to avoid potential effects of lexical or semantic association between one sentence and the following one), but the order of these sentences remained constant across participants.

\section{Procedure}

All children and adolescents were tested in the classroom. They were told to read the sentences and complete each one with the first word that came to mind that made sense, writing down the response in the booklet. The instructions emphasized that they did not have to think about it much. They were also encouraged to complete all items and not to look at what their classmates were writing. Younger participants were told to skip a sentence context if they had difficulties completing it. The second graders were helped with the task, so that when they had difficulties in reading and/or writing, it was the experimenter who wrote the words in the booklet.

All legible responses were registered in the data set. The words chosen by the participants were ranked for each sentence context, in an ascending order, according to their frequency (the number of times each word was used to complete a given sentence context relative to the total number of responses for that context). Sentence completion norms for children and adolescents are provided in the online supplement. For each valid response, cloze probability (the number of times the same word was chosen by a specific group for a given sentence context) was computed.

Additionally, in order to understand how the production of less common words and invalid responses differed across groups, the numbers of idiosyncratic (valid words generated by only 1 individual) and invalid (words that do not appropriately complete the sentence) responses were computed. Invalid responses were classified as structural or semantic errors. Structural errors were defined as final words that do not fit the previous context in a syntactically appropriate way (e.g., disagreement in number or gender, as in "The lady smells a perfumes"). Semantic errors represent sentence endings that do not fit the previous context in a semantically correct way (e.g., the final word has no semantic relationship with the subject and/or the verb of the sentence, as in "The grandmother prays a story"). Valid and inappropriate responses were identified after classification by three judges (the same ones who also classified sentence contexts as low or high constraint). Words were classified as invalid when at least two judges agreed that the word was not appropriate given the syntactic structure or semantic context of the sentence. 
Table 1

Statistical Comparisons ( $F$ and $p$ Values) of Cloze Probabilities in Children and Adolescents for Each Sentence Context

\begin{tabular}{|c|c|c|c|c|c|c|c|}
\hline \multirow[b]{2}{*}{ Number/Sentence Context } & \multirow[b]{2}{*}{ Final Word } & \multicolumn{2}{|c|}{ Children } & \multicolumn{2}{|c|}{ Adolescents } & \multirow[b]{2}{*}{$F$} & \multirow[b]{2}{*}{$p$} \\
\hline & & $M$ & $S D$ & $M$ & $S D$ & & \\
\hline 2. A cozinheira acende o... (The cook lights the ...) & Fogão (Cooker) & .73 & .45 & .85 & .36 & -2.11 & .036 \\
\hline 4. A criança bebe o... (The child drinks the ...) & Leite $($ Milk) & .75 & .43 & .95 & .22 & -4.07 & $<.001$ \\
\hline 6. A senhora cheira um ... (The lady smells a ...) & Perfume (Perfume) & .48 & .50 & 67 & .47 & -2.60 & .010 \\
\hline 7. A secretária atende o... (The secretary answers the ...) & Telefone (Phone) & .47 & .50 & .83 & .37 & -5.77 & $<.001$ \\
\hline 8. A pulseira enfeita o... (The bracelet decorates the... ) & Pulso (Wrist) & .44 & .50 & .60 & .49 & -2.22 & .028 \\
\hline 13. A costureira usa o... (The dressmaker uses the... ) & Dedal (Thimble) & .40 & .49 & .60 & .49 & -2.72 & .007 \\
\hline 14. A menina cala a ... (The girl shuts her ...) & Boca (Mouth) & .59 & .49 & .76 & .43 & -2.60 & .010 \\
\hline 15. A mulher veste uma... (The woman puts on $a \ldots$. . ) & Saia (Skirt) & .40 & .49 & .61 & .49 & -2.92 & $<.005$ \\
\hline 20. A batedeira mexe a ... (The mixer stirs the ... ) & Massa (Pastry) & .20 & .41 & .41 & .49 & -3.13 & $<.005$ \\
\hline 22. A abelha procura uma... (The bee looks for $a . .)$. & Flor (Flower) & .46 & .50 & .67 & .47 & -2.95 & $<.005$ \\
\hline 24. A mão espreme uma ... (The hand squeezes the . . out) & Laranja (Orange) & .47 & .50 & .73 & .44 & -3.76 & $<.001$ \\
\hline 34. O gato caça um ... (The cat hunts $a \ldots$... & Rato (Mouse) & .84 & .36 & .95 & .22 & -2.49 & .013 \\
\hline 37. O pintor pinta um ... (The painter paints $a \ldots)$ & Quadro (Painting) & .74 & .44 & .87 & .34 & -2.37 & .019 \\
\hline 40. O pasteleiro dá um ...(The confectioner gives $a .$. ) & Bolo (Cake) & .57 & .50 & .72 & .45 & -2.07 & .040 \\
\hline 44. O cão sacode a . . (The dog shakes the . . .) & Cauda (Tail) & .22 & .42 & .47 & .50 & -3.62 & $<.001$ \\
\hline 47. $\mathrm{O}$ vendedor varre a ... (The seller sweeps the ... ) & Loja (Shop) & .60 & .49 & .44 & .50 & 2.14 & .033 \\
\hline 50. O porteiro abre a ... (The doorkeeper opens the ... ) & Porta (Door) & .92 & .27 & .79 & .41 & 2.51 & .013 \\
\hline 53. O espelho mostra a ... (The mirror shows the ... ) & Cara (Face) & .54 & .50 & .37 & .49 & 2.44 & .016 \\
\hline $55 . \mathrm{O}$ árbitro segura o ... (The referee holds the ... ) & Apito (Whistle) & .58 & .50 & .81 & .39 & -3.68 & $<.001$ \\
\hline 56. A avestruz esconde a ... (The ostrich hides the ... ) & Cabeça (Head) & .21 & .41 & .44 & .50 & -3.44 & $<.001$ \\
\hline 62. O cachecol aquece o... (The scarf warms the ...) & Pescoço $(N e c k)$ & .80 & .40 & .92 & .29 & -2.24 & .026 \\
\hline 72. A mãe folheia a ... (The mother skims the ... ) & Revista (Magazine) & .24 & .43 & .59 & .49 & -5.11 & $<.001$ \\
\hline
\end{tabular}

Note-Only significant differences between groups are shown.

\section{RESULTS}

All valid final words, idiosyncratic responses, structural errors, and semantic errors for each sentence context and group are listed in the supplemental materials. Blanks and illegible responses $(1.41 \%$ for children and $0.42 \%$ for adolescents) were excluded from the analyses.

One-way ANOVAs were conducted in order to analyze group differences in the cloze probability ratings of the most selected word, as well as in the numbers of idiosyncratic responses and structural and semantic errors.

\section{Valid Responses With Higher Cloze Probability}

The supplemental materials show cloze probability values for all the valid responses in both groups - children and adolescents.

The word with the highest cloze probability for each sentence context was the same in both age groups for the majority of sentences. It is of note that in only 5 sentence contexts out of 73 did the most frequently selected word differ between groups (see the online supplement).

Age of acquisition and written frequency of the word with the highest cloze probability were collected from $\mathrm{Eu}-$ ropean Portuguese lexical databases (Marques, Fonseca, Morais, \& Pinto, 2007; Nascimento, Casteleiro, Marques, Barreto, \& Amaro, n.d.). Low age of acquisition ( $M=$ 1.95 years, $S D=0.55)$ and high written frequency $(M=$ $163.45, S D=229.51$ ) characterized these responses.

Despite the fact that the most chosen word was the same in children and adolescents, ANOVAs showed differences between groups for words with the highest cloze probability $[F(1,190)=18.86, p<.001]$. The cloze probability of these words was higher in the adolescent group $(M=.70$, $S D=.07)$ than in the children's group $(M=.66, S D=$ $.07)$, indicating that more participants in this group selected the same response. Significant group differences in cloze probability are shown in Table 1 . In 22 sentence contexts out of 73 , the cloze probability of the final word selected by the majority of individuals in each group was significantly different between children and adolescents, being higher in the older group.

\section{Idiosyncratic Responses}

Figure 1 presents the mean percentages of idiosyncratic responses for the groups of children and adolescents (also see the online supplement).

Statistical analysis revealed group differences in the numbers of idiosyncratic responses $[F(1,190)=7.12, p=$ .008]: A higher number of idiosyncratic responses was observed in children than in adolescents.

\section{Invalid Responses}

Figure 2 shows the percentages of invalid responses in children and adolescents (see also the online supplement).

\section{Idiosyncratic Responses}

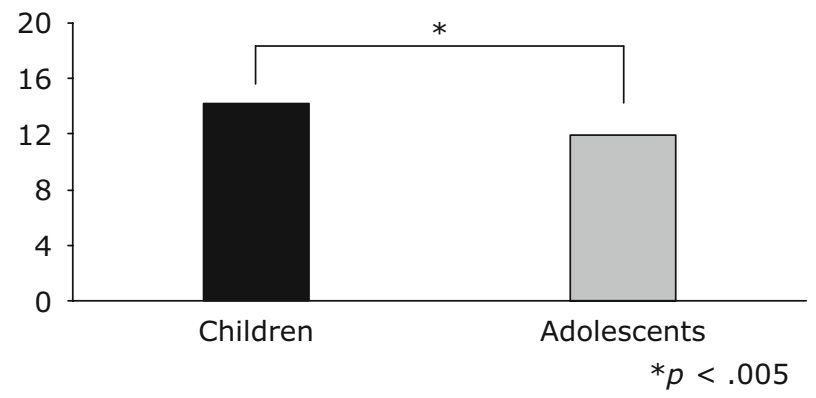

Figure 1. Mean number of idiosyncratic responses (\%) per age group (children and adolescents). 


\section{Incorrect Responses}

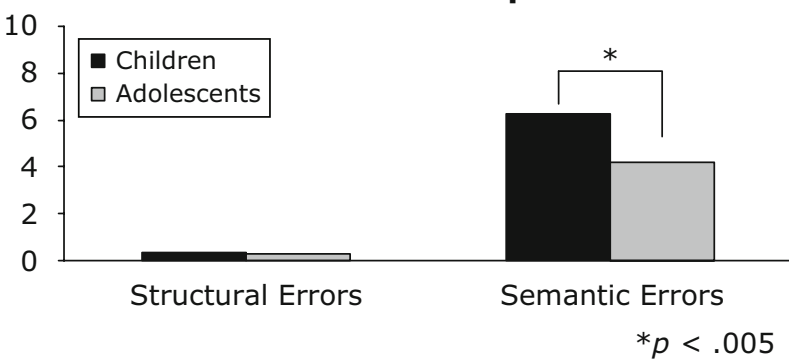

Figure 2. Mean numbers (\%) of structural and semantic errors per age group (children and adolescents).

No differences between groups were observed for structural errors (see Figure 2), which were almost nonexistent.

However, more semantic errors were found in the younger group than in adolescents $[F(1,190)=18.28$, $p=.000]$.

\section{Summary}

Overall, the findings point out that, as age progresses, the numbers of idiosyncratic and inappropriate responses decrease, whereas the number of common responses increases, as demonstrated by the cloze probability ratings. However, for the majority of the sentences, the final word most frequently evoked is similar across both age groups.

\section{DISCUSSION}

The present study aimed to accomplish a double goal: first, to contribute to the development of preliminary completion norms for 73 sentence contexts in European Portuguese that varied from high constraint (38) to low constraint (35); second, to explore developmental differences, from childhood to adolescence, in the cloze probability of the produced words, as well as in the number of idiosyncratic and invalid responses (structural and semantic errors).

Regarding developmental changes in the responses for the sentence completion task, the results of this study prompt two major conclusions: (1) During development, there is a reduction in the numbers of idiosyncratic responses and semantic errors; and, nonetheless, (2) there is an increased consistency in the type of appropriate final words chosen to complete a specific sentence context. Consistent with our hypotheses, these findings bring additional evidence for developmental differences in knowledge structures, which have implications for semantic memory organization and access, and for word selection, as in a sentence completion task.

On one hand, the fact that the majority of participants in each group chose the same word for almost all of the sentence contexts points to some consistency in word selection and seems to support the idea that early in development, humans have powerful learning mechanisms for extracting regularities in the environment and constructing common representations about things in the world and about how things work (Bates, Dale, \& Thal, 1995; Bates, Thal, \& Janowsky, 1992; Thomas \& Karmiloff-Smith, 2005).

On the other hand, even though the word chosen by the majority of participants in each group was almost always the same, cloze probability of final words was higher for adolescents, indicating that consistency in word selection tends to increase during development. As shown by studies on sentence comprehension, a given sentence context activates a set of semantic features related to it, because features of the category of the most expected exemplar are activated even before the presentation of the actual final word (e.g., DeLong et al., 2005; Van Petten, Coulson, Rubin, Plante, \& Parks, 1999). These results are corroborated electrophysiologically by a reduction of N400 amplitude to within-category violations (unexpected words that belong to the same semantic category as the expected exemplar) relative to between-category violations (unexpected words that do not belong to the same semantic category as the expected exemplar) (Federmeier \& Kutas, 1999a, 1999b).

A finding worth noting is that the most selected word for each sentence context, in both groups, had a low ageof-acquisition score. This finding is consistent with previous studies suggesting that words acquired early in life are processed faster and more accurately than words that are acquired later (e.g., Carroll \& White, 1973); arguably, such words can also be activated more quickly in the semantic network.

Moreover, the diversity and number of idiosyncratic responses diminished with age. These findings also corroborate previous studies that documented an increase of commonality of responses and paradigmatic responding with years of education (Rosenzweig, 1984; Sharp \& Cole, 1972). Clearly, differences in life experiences of participants can affect the availability of relevant concepts, as proposed by the PDP approach (Rogers \& McClelland, 2004). According to this model, daily experience modulates the weights of semantic units and, therefore, the structure of semantic knowledge. For example, it is known that education exerts its effects on word associations, since schooling promotes the learning of standard definitions of words, reducing the occurrence of atypical and incomplete semantic representations of word meaning (Burke \& Peters, 1986). This may explain the higher level of idiosyncratic responses in younger participants. Furthermore, another hypothesis to explain the higher production of uncommon or idiosyncratic responses in younger ages would be the representation of an incomplete or atypical word meaning (Burke \& Peters, 1986; Hunt, 1978). In fact, previous studies indicated differences in mental representations of words in the developing lexicon, compared with the fully developed lexicon (Charles-Luce \& Luce, 1990, 1995; Dollaghan, 1994; Metsala \& Walley, 1998; Storkel, 2002), and also a gradual refinement of conceptual knowledge, which is less based on scripts and is more abstract and categorically organized as age increases (e.g., Nation \& Snowling, 1999; Nelson, 1977, 1982). Together, these studies point to the interplay of individual (e.g., maturation) and contextual (e.g., education) factors on semantic and lexical development. 
Regarding semantic errors, their numbers were also different between age groups, indicating that semantic structure is being consolidated throughout development. These results may be explained by previous evidence stating that, during development, weak connections between semantic representations and lexical labels are found in the lexicon of younger children, in comparison with adolescents and adults (e.g., Gershkoff-Stowe, 2001; McGregor, 1997; McGregor, Friedman, Reilly, \& Newman, 2002; Plunkett, Karmiloff-Smith, Bates, Elman, \& Johnson, 1997). This same trend was found in studies on picture naming performance, which suggested a correlation between the depth of semantic knowledge and the success of word retrieval (Capone \& McGregor, 2005; McGregor et al., 2002).

Together, our findings point to developmental differences in word selection during a sentence completion task -in particular, in the numbers of semantic errors and idiosyncratic responses and the cloze probability of the words chosen by the majority of participants. Despite those differences, consistency in word selection was evident, as demonstrated by the fact that the same word was chosen by the majority of participants in both groups for almost all of the sentence contexts.

These norms are thus expected to contribute to cognitive and neurocognitive research using the European Portuguese language, either in the selection of stimuli for experimental paradigms, or in the assessment of responses provided by participants.

In spite of these contributions, caution should be taken when generalizing the norms for Portuguese-speaking populations in Africa and America, because cloze probabilities can be influenced by cultural and linguistic specificities, as pointed out by previous studies (see also Arcuri, Rabe-Hesketh, Morris, \& McGuire, 2001; Carneiro et al., 2004).

\section{AUTHOR NOTE}

This study was funded by a doctoral grant (SFRH/BD/35882/2007) from Fundação para a Ciência e a Tecnologia (Portugal) awarded to the first author. We are grateful to all the participants in this study and to the schools that authorized data collection. Special acknowledgment is due the anonymous reviewers for their helpful comments on an earlier version of the manuscript. Correspondence should be addressed to A. P. Pinheiro, Neuropsychophysiology Lab, CIPsi, School of Psychology, University of Minho, Campus de Gualtar, 4710-057 Braga, Portugal (e-mail: ana.pinheiro@psi.uminho.pt).

\section{REFERENCES}

Arcuri, S. M., Rabe-Hesketh, S., Morris, R. G., \& McGuire, P. K. (2001). Regional variation of cloze probabilities for sentence contexts. Behavior Research Methods, Instruments, \& Computers, 33, 80-90.

Bates, E., Dale, P. S., \& Thal, D. (1995). Individual differences and their implications for theories of language development. In P. Fletcher \& B. MacWhinney (Eds.), Handbook of child language (pp. 96-151). Oxford: Blackwell.

BATES, E., ThAL, D., \& JANOWSKY, J. (1992). Early language development and its neural correlates. In I. Rapin \& S. J. Segalowitz (Eds.), Handbook of neuropsychology: Vol. 7. Child neuropsychology (pp. 69110). Amsterdam: Elsevier.

Berndt, R. S., Mitchum, C. C., Haendiges, A. N., \& Sandson, J. (1997). Verb retrieval in aphasia: Characterizing single word impairments. Brain \& Language, 56, 68-106.

BJORKLUND, D. F. (1985). The role of conceptual knowledge in the development of organization in children's memory. In C. J. Brain- erd \& M. Pressley (Eds.), Basic processes in memory development: Progress in cognitive development research (pp. 103-142). New York: Springer.

BJORKLUND, D. F. (1987). How age changes in knowledge base contribute to the development of children's memory: An interpretive review. Developmental Review, 7, 93-130.

BJorkLund, D. F., \& Marchena, M. R. (1984). Developmental shifts in the basis of organization in memory: The role of associative versus categorical relatedness in children's free recall. Child Development, $\mathbf{5 5}, 952-962$.

BJORKLUND, D. F., \& SCHNEIDER, W. (1996). The interaction of knowledge, aptitude, and strategies in children's memory performance. $A d$ vances in Child Development \& Behavior, 26, 59-89.

Bloom, P. A., \& Fischler, I. (1980). Completion norms for 329 sentence contexts. Memory \& Cognition, 8, 631-642.

Burke, D. M., \& Peters, L. (1986). Word associations in old age: Evidence for consistency in semantic encoding during adulthood. Psychology \& Aging, 1, 282-292.

CApone, N. C., \& McGregor, K. K. (2005). The effect of semantic representation on toddlers' word retrieval. Journal of Speech, Language, \& Hearing Research, 48, 1468-1480.

Carneiro, M. P., Albuquerque, P., Fernandez, A., \& Esteves, F. (2004). Normas de associação livre de 16 palavras portuguesas para crianças de diferentes faixas etárias [Free association norms for 16 Portuguese words for children of different age groups]. Laboratório de Psicologia, 2, 49-78.

CARroll, J., \& White, M. (1973). Word frequency and age of acquisition as determiners of picture naming latency. Quarterly Journal of Experimental Psychology, 12, 85-95.

Charles-Luce, J., \& LuCE, P. A. (1990). Similarity neighbourhoods of words in young children's lexicons. Journal of Child Language, 17, 205-215.

Charles-Luce, J., \& Luce, P. A. (1995). An examination of similarity neighbourhoods in young children's receptive vocabularies. Journal of Child Language, 22, 727-735.

ChI, M. T. H., \& CeCI, S. J. (1987). Content knowledge: Its role, representation, and restructuring in memory development. Advances in Child Development \& Behavior, 20, 91-142.

Collins, A. M., \& Loftus, E. F. (1975). A spreading-activation theory of semantic processing. Psychological Review, 82, 407-428.

Collins, A. M., \& Quillian, M. R. (1969). Retrieval time from semantic memory. Journal of Verbal Learning \& Verbal Behavior, 8 , 240-247.

Connolly, J. F., Phillips, N. A., \& Forbes, K. A. K. (1995). The effects of phonological and semantic features of sentence-ending words on visual event-related brain potentials. Electroencephalography \& Clinical Neurophysiology, 94, 276-287.

Cramer, P. (1968). Word association. New York: Academic Press.

Cronin, V. S. (2002). The syntagmatic-paradigmatic shift and reading development. Journal of Child Language, 29, 189-204.

Curran, T., Tucker, D. M., Kutas, M., \& Posner, M. I. (1993). Topography of the N400: Brain electrical activity reflecting semantic expectancy. Electroencephalography \& Clinical Neurophysiology, 88, 188-209.

Delong, K. A., Urbach, T. P., \& Kutas, M. (2005). Probabilistic word pre-activation during language comprehension inferred from electrical brain activity. Nature Neuroscience, 8, 1117-1121.

Dollaghan, C. A. (1994). Children's phonological neighbourhoods: Half empty or half full? Journal of Child Language, 21, 257-271.

ElBRo, C. (1996). Early linguistic abilities and reading development: A review and a hypothesis. Reading \& Writing, 8, 453-485.

Federmeier, K. D., Kirson, D. A., Moreno, E. M., \& Kutas, M. (2001). Effects of transient, mild mood states on semantic memory organization and use: An event-related potential investigation in humans. Neuroscience Letters, 305, 149-152.

Federmeier, K. D., \& KutAs, M. (1999a). Right words and left words: Electrophysiological evidence for hemispheric differences in meaning processing. Cognitive Brain Research, 8, 373-392.

Federmeier, K. D., \& Kutas, M. (1999b). A rose by any other name: Long-term memory structure and sentence processing. Journal of Memory \& Language, 41, 469-495.

Federmeier, K. D., \& Kutas, M. (2001). Meaning and modality: Influences of context, semantic memory organization, and perceptual 
predictability on picture processing. Journal of Experimental Psychology: Learning, Memory, \& Cognition, 27, 202-224.

Federmeier, K. D., McLennan, D. B., De Ochoa, E., \& Kutas, M. (2002). The impact of semantic memory organization and sentence context information on spoken language processing by younger and older adults: An ERP study. Psychophysiology, 39, 133-146.

Francis, H. (1972). Toward an explanation of the syntagmaticparadigmatic shift. Child Development, 43, 949-958.

Gathercole, S. E., Willis, C. S., Emslie, H., \& Baddeley, A. D. (1992). Phonological memory and vocabulary development during the early school years: A longitudinal study. Developmental Psychology, 28, 887-898.

GershKoff-Stowe, L. (2001). The course of children's naming errors in early word learning. Journal of Cognition \& Development, 2, 131155.

Griffin, Z. M., \& Bock, K. (1998). Constraint, word frequency and the relationship between lexical processing levels in spoken word production. Journal of Memory \& Language, 38, 313-338.

Hagoort, P., Hald, L., Bastiaansen, M., \& Petersson, K. M. (2004). Integration of word meaning and world knowledge in language comprehension. Science, 304, 438-441.

Hunt, E. (1978). Mechanisms of verbal ability. Psychological Review, 85, 109-130.

Kamide, Y., Altmann, G. T. M., \& Haywood, S. L. (2003). The timecourse of prediction in incremental sentence processing: Evidence from anticipatory eye movements. Journal of Memory \& Language, 49, 133-156.

Kausler, D. H., \& Puckett, J. M. (1980). Frequency judgments and correlated cognitive abilities in young and elderly adults. Journal of Gerontology, 35, 376-382.

Kimble, M. O., Kaufman, M. L., Leonard, L. L., Nestor, P. G., Riggs, D. S., KaloupeK, D. G., ET AL. (2002). Sentence completion test in combat veterans with and without PTSD: Preliminary findings. Psychiatry Research, 113, 303-307.

Kircher, T. T. J., Bulimore, E. T., Brammer, M. J., Williams, S. C. R., Broome, M. R., Murray, R. M., ET AL. (2001). Differential activation of temporal cortex during sentence completion in schizophrenic patients with and without formal thought disorder. Schizophrenia Research, 50, 27-40.

Kleiman, G. M. (1980). Sentence frame contexts and lexical cooccurrence in aphasic sentence production. Applied Psycholinguistics, 19, 631-646.

Kohn, S. E., \& Cragnolino, A. (1998). The role of lexical co-ocurrence in aphasic sentence production. Applied Psycholinguistics, 19, 631646.

Kounios, J., \& Holcomb, P. J. (1992). Structure and process in semantic memory: Evidence from event-related brain potentials and reaction times. Journal of Experimental Psychology: General, 121, 459-479.

KutAs, M., \& HillyaRd, S. A. (1980). Reading senseless sentences: Brain potentials reflect semantic incongruity. Science, 207, 203-205.

Lahar, C. J., Tun, P. A., \& Wingfield, A. (2004). Sentence-final word completion norms for young, middle-aged, and older adults. Journals of Gerontology, 59B, P7-P10.

LiEBerMAN, P. (2002). On the nature and evolution of the neural bases of human language. American Journal of Physical Anthropology, 119(Suppl. 35), 36-62.

LoFTUS, E. F. (1973). Activation of semantic memory. American Journal of Psychology, 86, 331-337.

Macizo, P., Gómez-Ariza, C. J., \& BaJo, T. (2000). Associative norms of 58 Spanish words for children from 8 to 13 years old. Psicológica, 21, 287-300.

Markman, A. B., \& Dietrich, E. (2000). Extending the classical view of representation. Trends in Cognitive Sciences, 4, 470-475.

MarKMAN, E. M. (1990). Constraints children place on word meanings. Cognitive Science, 14, 57-77.

Markman, E. M., \& Hutchinson, J. E. (1984). Children's sensitivity to constraints in word meaning: Taxonomic versus thematic relations. Cognitive Psychology, 16, 1-27.

Marques, J. F., Fonseca, F. L., Morais, A. S., \& Pinto, I. A. (2007). Estimated age of acquisition norms for 834 Portuguese nouns and their relation with other psycholinguistic variables. Behavior Research Methods, 39, 439-444.

McDonald, S. A., \& Tamariz, M. (2002). Completion norms for 112
Spanish sentences. Behavior Research Methods, Instruments, \& Computers, 34, 128-137.

MCGREGOR, K. K. (1997). The nature of word-finding errors of preschoolers with and without word-finding deficits. Journal of Speech \& Hearing Research, 40, 1232-1244.

McGregor, K. K., Friedman, R. M., Reilly, R. M., \& Newman, R. M. (2002). Semantic representation and naming in young children. Journal of Speech, Language, \& Hearing Research, 45, 332-346.

Metsala, J. L., \& Walley, A. C. (1998). Spoken vocabulary growth and the segmental restructuring of lexical representations: Precursors to phonemic awareness and early reading ability. In J. L. Metsala \& L. C. Ehri (Eds.), Word recognition in beginning literacy (pp. 83-111). Mahwah, NJ: Erlbaum.

Munson, B., Swenson, C. L., \& Manthei, S. C. (2005). Lexical and phonological organization in children: Evidence from repetition tasks. Journal of Speech, Language, \& Hearing Research, 48, 108-124.

Nascimento, M. F. B., Casteleiro, J. M., Maroues, M. L. G., BarReto, F., \& Amaro, R. (n.d.). Corlex: Léxico de frequências do português [Lexical database]. Available at www.clul.ul.pt.

Nation, K., \& Snowling, M. J. (1999). Developmental differences in sensitivity to semantic relations among good and poor comprehenders: Evidence from semantic priming. Cognition, 70, B1-B13.

NebEs, R. D., \& Brady, C. B. (1991). The effect of contextual constraint on semantic judgements by Alzheimer patients. Cortex, 27, 237-246.

NeELy, J. H. (1991). Semantic priming effects in visual word recognition: A selective review of current findings and theories. In D. Besner \& R. Humphreys (Eds.), Basic processes in reading: Visual word recognition (pp. 264-336). Hillsdale, NJ: Erlbaum.

NeLson, K. (1977). The syntagmatic-paradigmatic shift revisited: A review of research and theory. Psychological Bulletin, 84, 93-116.

Nelson, K. (1982). The syntagmatics and paradigmatics of conceptual representation. In S. Kuczaj (Ed.), Language development: Language, thought, and culture (pp. 335-364). Hillsdale, NJ: Erlbaum.

Otten, M., Nieuwland, M. S., \& Van Berkum, J. J. (2007). Great expectations: Specific lexical anticipation influences the processing of spoken language. BMC Neuroscience, $\mathbf{8}, 89$.

OtTen, M., \& VAN Berkum, J. J. A. (2007). What makes a discourse constraining? A comparison between the effects of discourse message and priming on the N400. Brain Research, 1153, 166-177.

Petrey, K. (1977). Word associations and the development of lexical memory. Cognition, 5, 57-72.

Pickering, M. J., \& GARrod, S. (2007). Do people use language production to make predictions during comprehension? Trends in Cognitive Sciences, 11, 105-110.

Plunkett, K., Karmiloff-Smith, A., Bates, E., Elman, J. L., \& JoHnson, M. H. (1997). Connectionism and developmental psychology. Journal of Child Psychology \& Psychiatry, 38, 53-80.

Robichon, F., Besson, M., \& Faita, F. (1996). Completion norms for 744 French linguistic contexts of differing formats. Canadian Journal of Experimental Psychology, 50, 205-233.

Rogers, T. T., \& McClelland, J. L. (2004). Semantic cognition: A parallel distributed processing approach. Cambridge, MA: MIT Press.

Rosenzweig, M. (1984). Experience, memory, and the brain. American Psychologist, 39, 365-376.

SCHNEIDER, W., \& Pressley, W. (1997). Memory development between two and twenty (2nd ed.). Mahwah, NJ: Erlbaum.

SCHWANENFlugel, P. J. (1986). Completion norms for final words of sentences using a multiple production measure. Behavior Research Methods, Instruments, \& Computers, 18, 363-371.

Schwanenflugel, P. J., \& LaCount, K. L. (1988). Semantic relatedness and the scope of facilitation for upcoming words in sentences. Journal of Experimental Psychology: Learning, Memory, \& Cognition, 14, 344-354.

Schwanenflugel, P. J., \& Shoben, E. J. (1985). The influence of sentence constraint on the scope of facilitation for upcoming words Journal of Memory \& Language, 24, 232-252.

Schwantes, F. M., BoesL, S. L., \& Ritz, E. G. (1980). Children's use of context in word recognition: A psycholinguistic guessing game. Child Development, 51, 730-736.

Sharp, D., \& Cole, M. (1972). Patterns of responding in the word associations of West African children. Child Development, 43, 55-65.

Smiley, S. S., \& Brown, A. L. (1979). Conceptual preference for thematic or taxonomic relations: A nonmonotonic age trend from pre- 
school to old age. Journal of Experimental Child Psychology, 28, 249-257.

Stanovich, K. E., \& West, R. F. (1981). The effect of sentence context on ongoing word recognition: Tests of a two-process theory. Journal of Experimental Psychology: Human Perception \& Performance, 7, 658-672.

Stanovich, K. E., \& West, R. F. (1983). On priming by a sentence context. Journal of Experimental Psychology: General, 112, 1-36.

StORKEL, H. L. (2002). Restructuring of similarity neighbourhoods in the developing mental lexicon. Journal of Child Language, 29, 251-274.

StORKEL, H. L. (2009). Developmental differences in the effects of phonological, lexical and semantic variables on word learning by infants. Journal of Child Language, 36, 291-321.

Swingley, D. (2003). Phonetic detail in the developing lexicon. Language \& Speech, 46, 265-294.

TaRaban, R., \& McClelland, J. L. (1988). Constituent attachment and thematic role assignment in sentence processing: Influences of contentbased expectations. Journal of Memory \& Language, 27, 597-632.

TAYLOR, W. L. (1953). "Cloze" procedure: A new tool for measuring readability. Journalism Quarterly, 30, 415.

TAYLOR, W. L. (1956). Recent developments in the use of "cloze procedure." Journalism Quarterly, 33, 42-48.

Thomas, M. S. C., \& KarmilofF-Smith, A. (2002). Modelling typical and atypical cognitive development. In U. Goswami (Ed.), Handbook of childhood development (pp. 575-599). Malden, MA: Blackwell

Thomas, M. S. C., \& Karmiloff-Smith, A. (2003). Connectionist models of development, developmental disorders and individual differences. In R. J. Sternberg, J. Lautrey, \& T. Lubart (Eds.), Models of intelligence: International perspectives (pp. 133-150). Washington, DC: American Psychological Association.

Thomas, M. S. C., \& Karmiloff-Smith, A. (2005). Can developmental disorders reveal the component parts of the human language faculty? Language Learning \& Development, 1, 65-92.

Towse, J. N., Hamilton, Z., Hitch, G. J., \& Hutton, U. (2000). Sentence completion norms among adults: A corpus of sentences differing in length (Tech. Rep. CDRG7). London: Royal Holloway, University of London.

Towse, J. N., HutTon, U., \& Hitch, G. J. (1997). Humpty Dumpty had a great . . . banana? Children's sentence completions in a working memory reading task (Tech. Rep. CDRG1). London: Royal Holloway, University of London.

Towse, J. N., Hutton, U., \& Hitch, G. J. (1998). Grass is coloured . . red? Further sentence completion norms for children during a working memory reading task (Tech. Rep. CDRG3). London: Royal Holloway, University of London.
Van Berkum, J. J. A., Brown, C. M., Zwitserlood, P., Kooljman, V., \& HAGOORT, P. (2005). Anticipating upcoming words in discourse: Evidence from ERPs and reading times. Journal of Experimental Psychology: Learning, Memory, \& Cognition, 31, 443-467.

Van Berkum, J. J. A., Hagoort, P., \& Brown, C. M. (1999). Semantic integration in sentences and discourse: Evidence from the N400. Journal of Cognitive Neuroscience, 11, 657-671.

Van Berkum, J. J. A., Zwitserlood, P., Hagoort, P., \& Brown, C. M. (2003). When and how listeners relate a sentence to the wider discourse? Evidence from the N400 effect. Cognitive Brain Research, 17, 701-718.

VAN DEN BrinK, D., Brown, C. M., \& Hagoort, P. (2001). Electrophysiological evidence for early contextual influences during spokenword recognition: N200 versus N400 effects. Journal of Cognitive Neuroscience, 13, 967-985.

Van Petten, C., Coulson, S., Rubin, S., Plante, E., \& Parks, M. (1999). Time course of word identification and semantic integration in spoken language. Journal of Experimental Psychology: Learning, Memory, \& Cognition, 25, 394-417.

Vicente, S., Castro, S. L., \& Walley, A. (2003). A developmental analysis of similarity neighborhoods in European Portuguese. Journal of Portuguese Linguistics, 2, 93-114.

WeSt, R. F., \& StanOVICH, K. E. (1978). Automatic contextual facilitation in readers of three ages. Child Development, 49, 717-727.

West, R. F., Stanovich, K. E., Feeman, D. J., \& Cunningham, A. E. (1983). The effect of sentence context on word recognition in secondand sixth-grade children. Reading Research Quarterly, 19, 6-15.

Wicha, N. Y., Bates, E. A., Moreno, E. M., \& Kutas, M. (2003). Potato not Pope: Human brain potentials to gender expectation and agreement in Spanish spoken sentences. Neuroscience Letters, 346, 165-168.

Williams, J. N., \& Colombo, L. (1995). Constraints on the range of context-independent priming from ambiguous words. Psychological Research, 58, 38-50.

\section{SUPPLEMENTAL MATERIALS}

The full set of Portuguese sentence contexts and cloze probabilities discussed in this article may be downloaded from http://brm.psychonomic -journals.org/content/supplemental.

(Manuscript received March 21, 2010; revision accepted for publication June 20, 2010.) 